\title{
The relative importance of the gastrocnemius and soleus muscles in the ankle jerk of man
}

\author{
RAYMOND LEVY 1 \\ From the Neurological Unit, Northern General Hospital, Edinburgh
}

In many laboratory animals there is a clear structural and functional differentiation between 'red' and 'pale' muscle (Creed, Denny-Brown, Eccles, Liddell, and Sherrington, 1932). This differentiation is well exemplified by the triceps surae, which comprises the red soleus and the pale gastrocnemius. It has been known for a long time that these muscles differ functionally, both in the duration of their contraction and in their behaviour during reflex contraction (Denny-Brown, 1929; Creed et al., 1932), the soleus taking a greater part in this contraction than the gastrocnemius.

Although there is no very clear-cut structural difference between these muscles in man, Walls (1953) has shown that the total granularity (based on lipoid granule content) of the muscle fibres in the soleus was greater than those in the gastrocnemius. There has been a growing feeling, backed by very little experimental evidence, that some sort of functional differentiation exists (Tokizane, 1955; Bergamini, 1959).

Paillard (1955a, 1955b) has already noted casually that during his experiments on electrically induced reflex contraction of the calf muscles he preferred to place his electrodes on the soleus muscle; and a number of other workers (Denny-Brown, 1949; Joseph and Nightingale, 1952; Naponiello, 1957) have shown that, in the standing position, the activity of the soleus is much greater than that of the gastrocnemius, which is said by some (DennyBrown, 1949; Joseph and Nightingale, 1952) to be often entirely inactive.

This study was carried out in order to see whether, during a reflex contraction of the calf muscles, there was any difference in the relative participation of the soleus and gastrocnemius.

\section{METHODS}

The subject lay prone, with his feet hanging over the edge of a couch and resting against a hinged board. The ankle jerk was produced by a weight falling from a constant 'Present address: The Maudsley Hospital, Denmark Hill, London,
S.E.5. height on to the Achilles tendon. The weight was held up by stiff elastic bands, to ensure that it only remained in contact with the ankle for a brief instant. The difficulty in standardizing the ankle jerk adequately arises mainly from factors outside the experimenter's control, viz., physical differences in the tissues intervening between the hammer and the tendon. In spite of these difficulties, reasonably consistent results can be obtained in any one subject, using this method. Superficial electrodes were used to record the electromyographic response of the muscle. This was preferred to needle electrodes, as it was considered that a better assessment of the behaviour of $N$ the whole muscle would be obtained in this way. The $N$ electrodes consisted of small chlorided silver cups coro $\vec{A}$ taining Cambridge electrode jelly. They were fixed with $\infty$ adhesive tape to the skin overlying the muscle. One pa需음 of electrodes was placed over the medial head of the gastrocnemius muscle about one third of the way dow the leg and the other over the soleus almost at the latera border of the posterior compartment about half way dow the leg. The inter-electrode distance was $3 \mathrm{~cm}$. In some the early experiments recordings were also taken with monopolar electrodes, an indifferent electrode being placed on the external malleolus (in the case of the soleus) and on the head of the fibula (in the case of the gastrocnemius). Since the results obtained in this way did not differ appreciably from those obtained with bipolar recording, and since it led to difficulties with stimulus artefact and $50 \mathrm{c} / \mathrm{s}$ interference, this method was abandoned. The output was led through a standard Ediswan portable E.E.G. amplifer to a cathode ray oscilloscope. The jerk was recorded by means of a moving anode mechano-electric transducer RCA 5734 (Johns, 1956), the output of which can be led unamplified to the cathode ray oscilloscope. The medial popliteal nerve was stimulated with square pulses of $1 \mathrm{msec}$. duration from a constant-current stimulator. The current was increased until the electromyograph showed a deflection approximately $30 \mathrm{msec}$. after the stimulus artefact. This, the ' $H$ ' wave of Magladery and McDougal (1950), has been shown by these workers to be caused by a reflex contraction of the calf muscles set off by stimulation of the $D$ afferent fibres in the medial popliteal nerve. If the strength of the current was increased, another deflection preceded this wave. This wave has been shown to be $\mathcal{N}$ caused by a contraction of the muscle set off by direct $N$ stimulation of the motor fibres in the nerve and has been $N$ called the ' $M$ ' wave (Magladery and McDougal, 1950). 


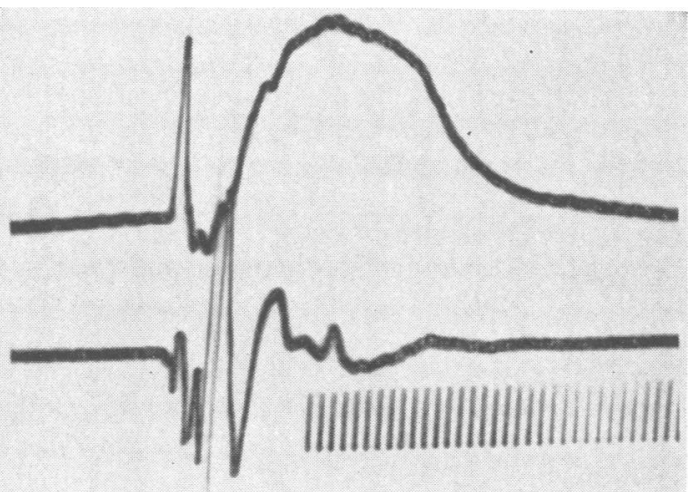

FIG. 1a
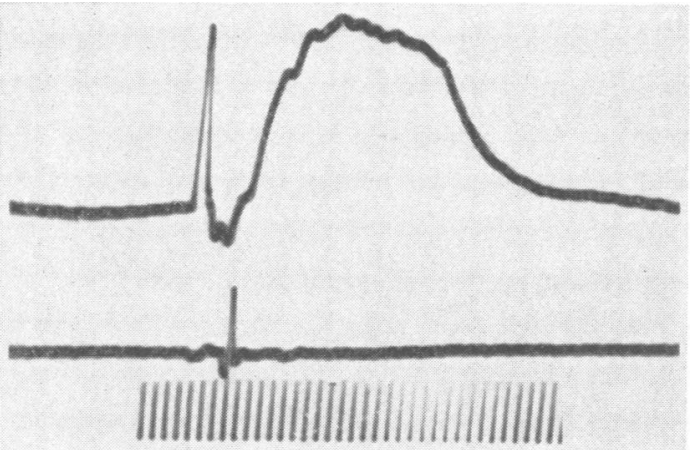

FIG. $1 \mathrm{~b}$

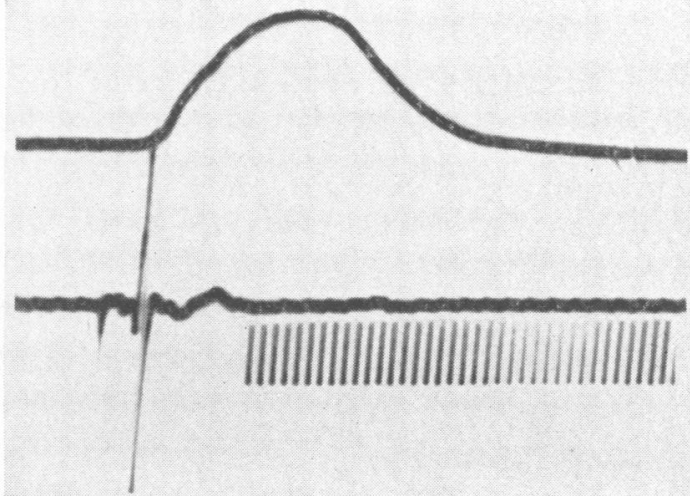

FIG. $2 \mathrm{a}$

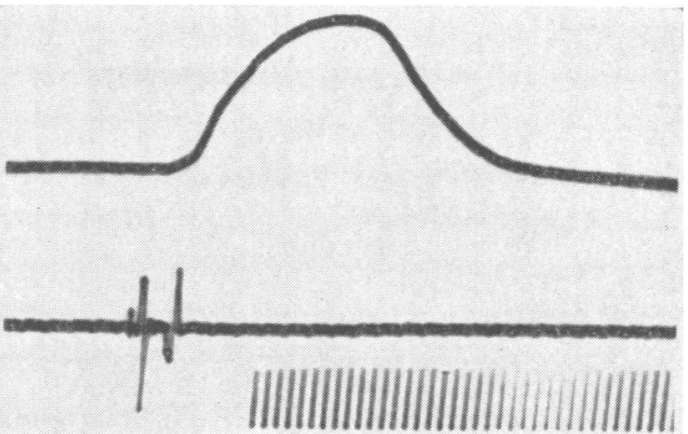

FIG. 2b

FIG. 1. a Electromyographic response of the soleus muscle (lower trace) during the ankle jerk (tension record on top trace). Time $100 \mathrm{c} / \mathrm{s}$. b Same from the gastrocnemius muscle.

FIG. 2. a The ' $H$ ' wave recorded over the soleus muscle (lower trace) and the associated displacement of the foot (top trace). Times $100 \mathrm{c} / \mathrm{s}$.

b The ' $H$ ' wave recorded over the gastrocnemius muscle (lower trace) and the associated displacement of the foot (top trace). Time $100 \mathrm{c} / \mathrm{s}$.
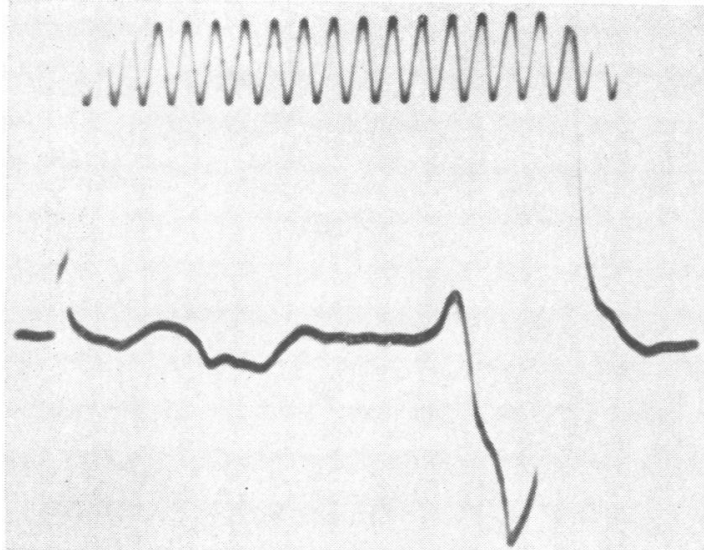

FIG. 3a
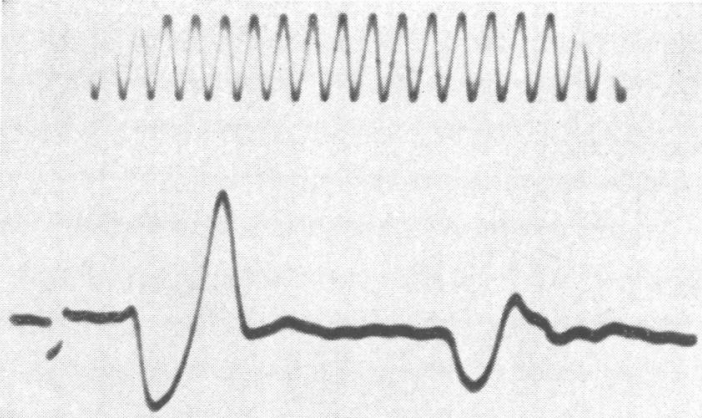

FIG. $3 b$

FIG. 3. a The ' $M$ ' and ' $H$ ' waves as recorded over the soleus muscle. Time $500 \mathrm{c} / \mathrm{s}$.

b The ' $M$ ' and ' $H$ ' waves as recorded over the gastrocnemius muscle. Time $500 \mathrm{c} / \mathrm{s}$. 


\section{RESULTS}

Twelve normal subjects were used. In every case both legs were tested. Fig. 1 is an example of the type of record obtained. In every instance the electromyograph of the ankle jerk showed a consistently greater deflection when the record was taken from the soleus than when it was taken from the gastrocnemius. The jerk itself was constant throughout, as is shown by the tension record.

The same applied to the ' $\mathrm{H}$ ' wave. For an equal contraction it was consistently greater on the record obtained from the soleus than in that obtained from the gastrocnemius (Fig. 2).

The reverse applied to the ' $M$ ' wave, which was always larger in the gastrocnemius record than in the soleus record (Fig. 3).

When the stimulus was increased so as to produce a maximal ' $H$ ' wave, this was again larger in the soleus. The threshold for reflex contraction, however, was not appreciably different in the two muscles, whether the stimulus was mechanical or electrical.

\section{DISCUSSION}

It appears therefore that during a reflex contraction in man a larger action potential is recordable from the soleus than from the gastrocnemius. That this is not due to extraneous factors, like any difference in the resistance of the tissues overlying the two muscles, is suggested by the fact that direct stimulation of the motor fibres produced a larger action potential (' $M$ ' wave) in the gastrocnemius. The results are, therefore, in keeping with those of animal experiments. Eccles, Eccles, and Lundberg (1958) found that in the cat motor neurones of 'red' muscles had a larger total monosynaptic excitatory post-synaptic potential than those of 'pale' muscles. This may be linked to the fact that, at least in animals, the density of muscle spindles is greater in the soleus muscle (Hagbarth and Wohlfart, 1952; Swett and Eldred, 1960; Cooper, 1960). This muscle may therefore be expected to be more sensitive to stretch than the gastrocnemius.

Unfortunately, it is impossible to tell whether the greater electrical activity of the soleus is necessarily associated with a greater contraction, since such an analysis would require the dissection of the respective tendons and a direct recording of the tension developed by each muscle. This is obviously not feasible in man. However, it seems reasonable to assume that a greater contraction does, in fact, occur.

The results do, at any rate, suggest that there is a difference in the behaviour of these two muscles during a reflex contraction, and this is consistent with the greater activity of the soleus in standing (Denny-Brown, 1949; Joseph and Nightingale, 1952; Naponiello, 1957), since normal posture must be based on the stretch reflex.

\section{SUMMARY}

In 12 normal subjects the composite action potential recorded by means of skin electrodes during a reflex contraction was greater over the soleus than over the gastrocnemius. It is suggested that the soleus plays a greater part in the production of the ankle jerk.

I wish to thank Dr. J. A. Simpson for his help and encouragement. This work was supported by a gran $\vec{D} \vec{f}$ from the Scottish Hospitals Endowments Research Trus@ $\infty$

\section{REFERENCES}

Bergamini, V. (1959). Riv. Pat. nerv. ment., 80, 708.

Cooper, S. (1960). In The Structure and Function of Muscle, edited be G. H. Bourne, vol. 1, p. 393. Academic Press, New York ant London.

Creed, R. S., Denny-Brown, D., Eccles, J. C., Liddell, E. G. T., an⿳亠口冋 Sherrington, C. S. (1932). Reflex Activity of the Spinal Cord. Oxford University Press, London.

Denny-Brown, D. E. (1929). Proc. roy. Soc. B, 104, 371.

(1949). Arch. Neurol. Psychiat. (Chic.), 61, 99.

Eccles, J. C., Eccles, R. M., and Lundberg, A. (1958). J. Physiol. (Lond.), 142, 275.

Hagbarth, K. E., and Wohlfart, G. (1952). Acta anat. (Basel), 15, 85. Johns, R. J. (1956). Electroenceph. clin. Neurophysiol., 8, 339.

Joseph, J., and Nightingale, A. (1952). J. Physiol. (Lond.), 117, 484. Magladery, J. W., and McDougal, D. B. (1950). Johns Hopk. Hosp. Bull., 86, 265.

Naponiello, L. V. (1957). Anat. Rec., 127, 339.

Paillard, J. (1955a). Réflexes et Régulations d'Origine proprioceptive chez l'homme. Arnette, Paris.

- (1955b). Pfiügers. Arch. ges. Physiol., 260, 448.

Swett, J. E., and Eldred, E. (1960). Anat. Rec., 137, 453.

Tokizane, T. (1955). Clinical Electromyography. Kyodo, Ishe, Tokyo.

Walls, E. W. (1953). J. Anat. (Lond.), 87, 437. 